\title{
A REPRESENTAÇÃO DA MULHER NAS CAPAS DA ELLE BRASIL: UMA HISTÓRIA DE AUSÊNCIAS
}

\author{
Woman representativeness in Elle Brasil covers: a history of absences \\ La representación de la mujer en las portadas de Elle Brasil: una historia de \\ ausencias
}

Renata Barreto Malta

Professora Doutora da Universidade Federal de Sergipe renatamaltarm@gmail.com

Carla Jullyene Lima Santos

Graduada em Publicidade e Propaganda pela Universidade Federal de Sergipe karlalimaufs@gmail.com

\section{Maria Nayane de Sousa Pinto}

Graduada em Publicidade e Propaganda pela Universidade Federal de Sergipe nayanesousa91@gmail.com

\section{Resumo}

Este estudo propõe analisar as capas da revista ELLE Brasil, ao longo dos seus 28 anos, de forma objetiva e comparativa, mensurando a frequência das aparições de modelos de representação e interpretando qualitativamente os dados. Como método, aplicamos a Análise de Conteúdo do corpus, criteriosamente selecionado. Concluímos que, em sua história, a revista expressa uma representação quase que uníssona, privilegiando corpos magros de mulheres brancas, sendo a representatividade da mulher negra e seus traços fenotípicos praticamente inexistente. Contudo, em uma análise acurada da última década, a pluralidade de representações se fez presente, pela primeira vez, possivelmente um fenômeno em emergência.

Palavras-chave: Gênero, raça e etnia. Representatividade. Análise de Conteúdo. ELLE Brasil.

\begin{abstract}
This study proposes to analyze the ELLE Brasil covers, throughout its 28 years, in an objective and comparative way, measuring the frequency of the sightings, which represent models of representation, and qualitatively interpreting the data. As a method, it has been applied the Content Analysis of the corpus, carefully selected. We have concluded that over the years there was an almost unisonous representativeness, privileging slim bodies of white
\end{abstract}


women. The black women representation and their phenotypes were practically unseen in ELLE Brasil covers. However, in an accurate analysis of the last decade, the plurality of representations was shown, for the first time, possibly an emerging phenomenon.

Key words: Gender; race and ethnicity. Representativeness. Content Analysis. ELLE Brasil.

\section{Resumen}

Este estudio propone analizar las portadas de la revista ELLE Brasil, a lo largo de sus 28 años, de forma objetiva y comparativa, mensurando la frecuencia de las apariciones de modelos de representación e interpretando cualitativamente los datos. Como método, aplicamos el Análisis de Contenido del corpus, criteriosamente seleccionado. Concluimos que, en su historia, la revista expresa una representación casi que unísona, privilegiando cuerpos delgados de mujeres blancas, siendo la representatividad de la mujer negra y sus rasgos fenotípicos prácticamente inexistente. Sin embargo, en un análisis cuidadoso de la última década, la pluralidad de representaciones se hizo presente, por primera vez, posiblemente un fenómeno en emergencia.

Palabras clave: Género, raza y etnia. Representatividad. Análisis de Contenido. ELLE Brasil.

\section{INTRODUÇÃO}

A identidade e os sistemas de representação são os pontos de partida, e centrais, desse estudo. A primeira é um processo composto pelos mais variados fatores influenciadores e mutáveis, considerando que "a identidade é um desses conceitos que operam 'sob rasura', no intervalo entre a inversão e a emergência: uma ideia que não pode ser pensada da forma antiga, mas sem a qual certas questões-chave não podem ser sequer pensadas" (HALL, 2006, p. 104). É preciso, então, ponderar que não existe uma unidade fixa, as identidades na contemporaneidade são fragmentadas e fraturadas, construídas por meio de discursos, práticas e posições, passíveis de congruências e/ou antagonismos. Nesse contexto, o sistema de representação tem papel fundamental. Nas palavras de Silva (2007, p.91), "representar significa, nesse caso, dizer: 'essa é a identidade', 'a identidade é isso'. Os discursos, os quais compõem os sistemas de representação, apresentam ambientes onde, potencialmente, sujeitos podem se posicionar. Partindo dessa premissa, a representação adquire grande relevância e se torna instrumento de dominação e poder. "Quem tem o poder de representar tem o poder de definir e determinar a identidade" (SILVA, 2007, p.91). 
A identidade possui, então, um senso de reconhecimento dos significados, a partir de um sentimento de pertencimento, que lhe permite absorver informações para o interior do seu discurso pessoal, ou melhor, para o interior do seu processo de formação identitária. Entendemos que os meios de comunicação são importantes sistemas simbólicos de representação e que, especificamente, as revistas femininas de moda e "beleza", apresentam discursos capazes de contribuir para a percepção social do que é hegemonicamente considerado ideal - beleza, corpo, comportamento ideais.

Esse argumento nos direciona ao objeto de análise do presente artigo, a revista ELLE ${ }^{1}$ Brasil, publicada no país há quase três décadas e uma das revistas de moda mais influentes do mundo. Assim, além de uma revisão bibliográfica de autores que contribuam para a fundamentação teórica, propomos uma pesquisa empírica, analisar as capas da Revista ELLE Brasil, especificamente as imagens das mulheres representadas nas capas publicadas desde o seu lançamento no país.

Partimos, assim, da premissa de que o universo das publicações femininas, principalmente quando voltadas ao mundo da moda, tendem a estabelecer padrões estéticos e comportamentais que, de alguma forma, serão absorvidos pelas suas leitoras e que, consequentemente, poderão ser reproduzidos no cotidiano das mesmas (CARNEIRO, 2003; p. 119). Assim, a mídia, ao representar, passa a ser parte importante no processo de construção identitária.

Ao analisar, buscaremos compreender quais são os modelos de mulher que compõem essas publicações no que se refere a aspectos étnico, biótipo, fenótipo, assim como aqueles mais subjetivos que permeiam a representação. Para tanto, propomos como método a Análise de Conteúdo, aplicada em um corpus criteriosamente selecionado, realizada em duas etapas, uma quantitativa, e outra qualitativa, visando apresentar dados que demonstrem a frequência das formas de representação identificadas e categorizadas, assim como a discussão qualitativa dos resultados.

\section{IDENTIDADE E REPRESENTAÇÃO NAS RELAÇÕES DE GÊNERO, RAÇA E ETNIA}

Podemos afirmar que o contexto contemporâneo não está centrado em um conceito de identidade uníssona, essencial e imutável. Nesse universo cambiante, focamos nossas

\footnotetext{
${ }^{1}$ Título da revista colocado em caixa alta devido ao modo como a publicação apresenta sua marca.
} 
atenções especificamente nas identidades de gênero e suas representações, de forma interseccional a raça e etnia, considerando os objetivos da presente pesquisa. Segundo Louro (1999, p.12), “somos sujeitos de identidades transitórias e contingentes. Portanto, as identidades sexuais e de gênero (como todas as identidades sociais) têm o caráter fragmentado, instável, histórico e plural”.

Judith Butler (2015) se aprofunda nessa questão, refletindo sobre como a sociedade opera a partir de uma definição simplista e reducionista do que seria a identidade de gênero.

Se alguém "é" uma mulher, isso certamente não é tudo o que esse alguém é; o termo não logra ser exaustivo, não porque os traços predefinidos de gênero da "pessoa" transcendam a parafernália específica de seu gênero, mas porque o gênero nem sempre se constitui de maneira coerente ou consistente nos diferentes contextos históricos, e porque o gênero estabelece interseções com modalidades raciais, classistas, étnicas, sexuais e regionais de identidades discursivamente constituídas. Resulta que se tornou impossível separar a noção de "gênero" das interseções políticas e culturais em que invariavelmente ela é produzida e mantida (BUTLER, 2015, p. 21).

Essa concepção acaba por refletir nos sistemas de representação, principalmente nos midiáticos, objeto central do presente estudo. Carneiro (2003) acentua a necessidade de uma representação plural, principalmente no que concerne questões étnicas e raciais, que muitas vezes não são representadas nem mesmo dentro do discurso político do feminismo, ao desconsiderar essas diferenças quando se constrói a identidade das "mulheres" defendida pelo movimento.

Ao politizar as desigualdades de gênero, o feminismo transforma as mulheres em novos sujeitos políticos. Essa condição faz com que esses sujeitos assumam, a partir do lugar em que estão inseridos, diversos olhares que desencadeiam processos particulares subjacentes na luta de cada grupo particular. Ou seja, grupos de mulheres indígenas e grupos de mulheres negras, por exemplo, possuem demandas específicas que, essencialmente, não podem ser tratadas, exclusivamente, sob a rubrica da questão de gênero se esta não levar em conta as especificidades que definem o ser mulher neste e naquele caso. Essas óticas particulares vêm exigindo, paulatinamente, práticas igualmente diversas que ampliem a concepção e o protagonismo feminista na sociedade brasileira, salvaguardando as especificidades. (CARNEIRO, 2003, p. 119).

A autora ainda ressalta o fato de que o racismo, por exemplo, atua na relação entre os gêneros de forma interseccional, privilegiando mulheres brancas em detrimento das negras, a partir da exploração e exclusão dos subalternos, instituindo aos hegemônicos padrões altíssimos, ou melhor, inalcançáveis dentro de uma competição que deveria ser igualitária. Um exemplo disso é o uso excessivo da imagem "europeizada" de mulheres em veículos de 
comunicação no Brasil. Essa é uma discussão de fundamental importância para a presente pesquisa, considerando que o objeto do estudo em questão é uma revista francesa que se insere no mercado brasileiro, impactando a sociedade por meio de suas representações. Assim, entendemos que para fundamentação teórica aqui proposta, adentrar em raça e etnia como alicerces sociais de disputa de poder se mostra significativo.

Nesse jogo, reforçamos o caráter político de todos os atores de disputa, mesmo aqueles que, à primeira vista, parecem oriundos de essencialismos, como raça. Tendo como parâmetro os Estudos Culturais, seu conceito vai muito além de um significado cientifico, faz parte de uma construção política e social. Nas palavras de Hall (2003), raça:

É a categoria discursiva em torno da qual se organiza um sistema de poder socioeconômico, de exploração e exclusão - ou seja, o racismo. Contudo, como prática discursiva, o racismo possui uma lógica própria. Tenta justificar as diferenças sociais e culturais que legitimam a exclusão racial em termos de distinções genéticas e biológicas, isto é, na natureza. Esse "efeito de naturalização" parece transformar a diferença racial em um "fato" fixo e cientifico, que não responde à mudança ou à engenharia social reformista. Essa referência discursiva à natureza é algo que o racismo contra o negro compartilha com o antissemitismo e com o sexíssimo (em que também "a biologia é o destino(...)" (HALL, 2003, p. 69).

Já o termo etnia faz alusão ao âmbito antropológico. Uma comunidade humana é considerada um grupo étnico por apresentar equivalentes linguísticos, culturais e semelhanças genéticas, portanto raça e etnia entrelaçam seu significado e formam estruturas sociais que, embora não possuam o mesmo sentido, confluem em grande medida, isso porque o preconceito étnico e o racismo são, muitas, vezes, fruto das mesmas relações de poder que elegem privilegiados e pretere grupos sociais. No Brasil, segundo Oracy Nogueira (2006), vivenciamos o denominado racismo "de marca", que vai revelar a sua prática de discriminação justificada nos fenótipos, tendo a raça branca como modelo idealizado. Assim, quanto mais traços negroides a pessoa apresentar, mais racismo ela sofre.

No entanto, como afirma Nascimento (1978), a nossa sociedade mantém uma suposta democracia racial, que, na verdade, deve ser compreendida como “(...) a metáfora perfeita para designar o racismo estilo brasileiro(...)" (NASCIMENTO,1978, p. 41), caracterizado como um racismo velado, não explicitado pelos opressores, porém sentido e vivido em todas as esferas sociais, e com maior intensidade pelas classes sociais menos favorecidas e pelas mulheres, considerando que a base da pirâmide social é constituída por mulheres negras. Pontuamos que o presente trabalho não tem a pretensão de realizar um levantamento histórico acerca do racismo no Brasil, ainda que este seja de grande importância, mas sim discutir a 
representação, ou falta dela, de mulheres negras na mídia, especificamente no objeto pesquisado.

Essas contribuições teóricas se mostram importantes para a pesquisa na medida que, em primeira instância, propomos quantificar a presença/ausência da mulher negra no corpus analisado e, mais além, qualificar sua representação, compreendendo modelos e padrões que, possivelmente, componham o discurso de beleza, o qual potencialmente impacta a sociedade. Para Alajika (2012; p. 120), " a mídia pode ser considerada um agentel fator fundamental na alteração do comportamento, interferindo inclusive no próprio processo de emergência da identidade". Woodward (2007) também reforça o fato da mídia ter papel determinante na maneira como o sujeito se posiciona socialmente. Abrimos espaço, então, para centrar-nos em um meio de comunicação em especifico, considerando a proposta da presente pesquisa, as revistas que se voltam para o público feminino.

Entendemos que estas produções culturais tendem a comunicar modelos de beleza e comportamento, como bem pontuamos, enaltecendo o corpo ideal, determinado por padrões estéticos. Segundo Felerico (2010), o corpo assume um papel fundamental na sociedade do século XX, envolto aos processos de identidade e socialização, assim como os reflexos de formação estereotípica e de culto ao corpo. O culto ao corpo é aqui definido como um conjunto de práticas e cuidados, os quais chegam a ser ritualísticos, e que tem como cerne a maior aproximação possível de um padrão de beleza estabelecido socialmente, o qual se alicerça nas relações de poder que operam em sociedade, posicionando a pele clara, os cabelos lisos, as formas retilíneas e a magreza como ideais de corpo belo e desejável na contemporaneidade. Assim, o padrão de beleza não é aleatoriamente definido, nem mesmo determinado pelo "gosto", mas alinhado a etnias dominantes e seus traços fenotípicos.

\section{REVISTA ELLE BRASIL}

A revista ELLE, objeto do presente estudo, nasceu na França, em 1945, com a proposta de trazer um conteúdo o qual supostamente ampliaria o universo restrito das mulheres naquele momento sócio histórico. Presente em 43 países, chegou ao Brasil em maio de 1988 e é uma das revistas mais conceituadas do segmento de moda no mundo, sendo a primeira em número de vendas no mercado mundial - mais de 6 milhões de exemplares por 
mês ${ }^{2}$. A revista se declara irreverente e ousada, apostando em inovação, além de afirmar em seu site que aproxima o luxo da mulher real.

Seu site está vinculado ao portal M de Mulher, que disponibiliza conteúdo focado exclusivamente no público feminino e possui 716.000 views mensais. No Brasil, a ELLE possui mais de 145.000 leitores. As revistas são vendidas, em sua maior parte, nas regiões sudeste, sul e nordeste e seu público é constituído principalmente por mulheres (89\%).

Estes dados revelam a pertinência do objeto analisado e sua potencial influência como meio de comunicação. Assim, compreender os modelos de representação que compõem as capas da revista ELLE, em 28 anos de história no mercado brasileiro, se mostra significativo, partindo da premissa de que esse veículo é parte formativa do sistema simbólico de representação que impacta a sociedade.

\section{METODOLOGIA}

No sendeiro do empírico, como bem pontuamos, apresentamos como objetivo verificar como se deu a representação das capas da Revista ELLE ao longo de sua história no Brasil. Entendemos que a capa é o espaço destinado a dar visibilidade ao conteúdo de maior relevância daquela produção e, assim, tem a intenção de chamar a atenção do leitor. Ressaltamos que as representações que ocupam a capa devem ser observadas com maior afinco, pois retratam o todo e possuem maior potencial de impacto.

Definimos como corpus 35 capas de cada década, desde a chegada da revista ELLE ao Brasil, sendo que na década de 80 trabalhamos com o universo total, considerando que a revista publicou sua primeira edição em maio de 1988 e possui uma periodicidade mensal. O sorteio randômico da amostra garante-nos representatividade e possibilidade de generalização dos resultados. Estipulou-se, cientifica e estatisticamente, que para que uma amostra seja probabilística e generalizável é necessário que todos os membros da população do grupo a ser estudado tenham as mesmas chances de serem selecionados e que esta amostra seja formada por pelo menos 35 integrantes deste grupo, independentemente do tamanho da população inicial (AAKER, 2004). Além da análise do primeiro corpus, decidimos analisar, também, todas as capas de edição de aniversário, publicadas anualmente em maio desde 1988, por serem edições especiais, mais robustas, compondo, assim, nosso segundo corpus de análise. Deparamo-nos com algumas capas estampadas por homens ou por grupos de pessoas que

\footnotetext{
${ }^{2}$ http://publiabril.abril.com.br/marcas/elle
} 
continham homens. Como o intuito das análises era identificar a mulher representada pela revista, essas capas foram retiradas do universo total.

Definimos como método a Análise de Conteúdo, realizada em duas etapas, uma quantitativa e outra qualitativa. Pontuamos que a Análise de Conteúdo é um método que busca descrever e interpretar determinado conteúdo dentro de uma classe de documentos e textos, conduzindo descrições sistemáticas, qualitativas e/ou quantitativas.

Optamos pela sistematização por categorias, a qual corrobora para uma maior organização dos elementos identificados. O trabalho de codificação desenvolvido pelo analista é, para Bardin (1997), como uma poda, uma seleção das unidades a serem codificadas. $\mathrm{Na}$ fase qualitativa, interpretaremos os dados obtidos, assim como o detalhamento de cada categoria codificada, apresentando a discussão dos resultados, buscando aprofundamento e embasamento teórico de autores que possam alicerçar resultados empíricos.

\section{ANÁLISES E DISCUSSÃO DOS RESULTADOS}

A fase das análises, como prevíamos, resultou em uma grande quantidade de dados acerca das representações do gênero feminino, tendo o corpus como base. Por se tratar de um artigo, não poderemos, aqui, expor todos os achados decorrentes dessa pesquisa, assim, apresentaremos os dados mais significativos, acompanhados da discussão dos resultados, com gráficos produzidos a partir da mensuração de frequência das categorias analisadas, primeiramente traduzindo resultados gerais e depois comparativos. O primeiro conjunto de gráficos diz respeito ao primeiro corpus e, o segundo, refere-se às capas que compõem as edições de aniversário da revista.
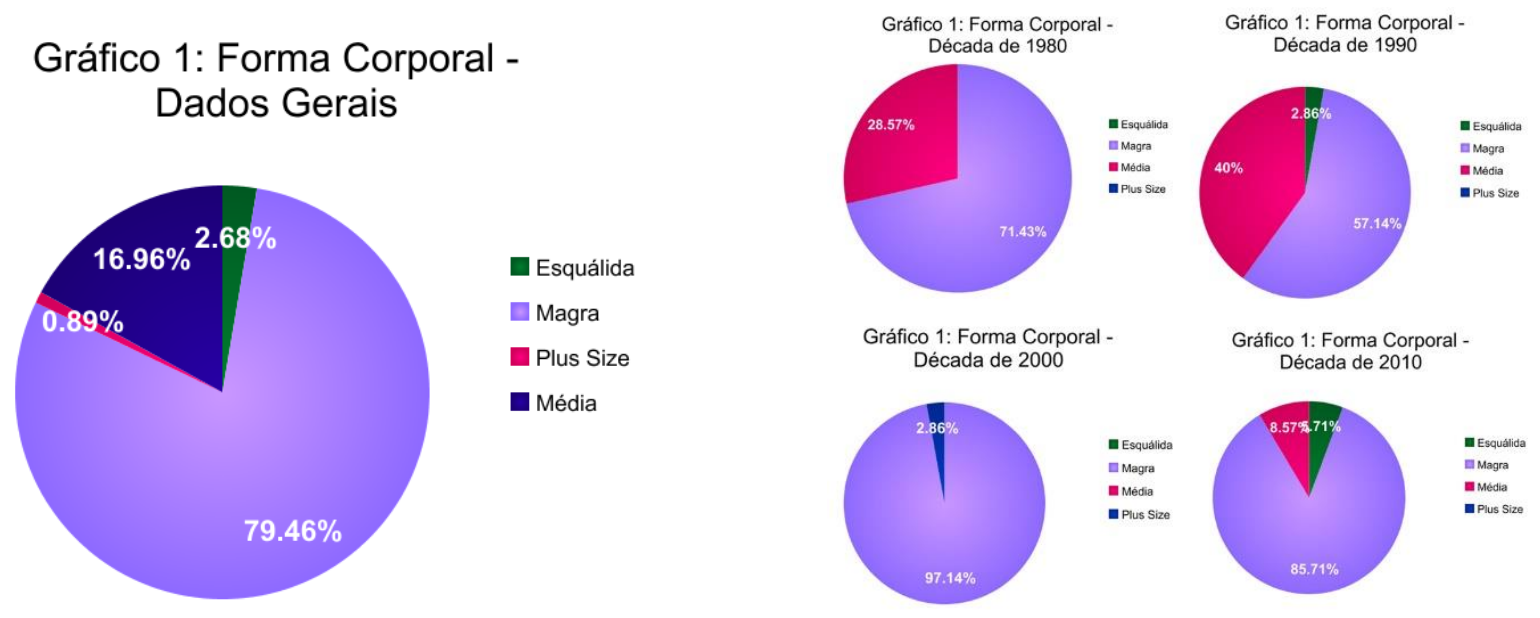

Esquálida Magra $\square$ Média $\square$ Plus Size 


\section{Gráfico: Forma Corporal - Edições de Aniversário}

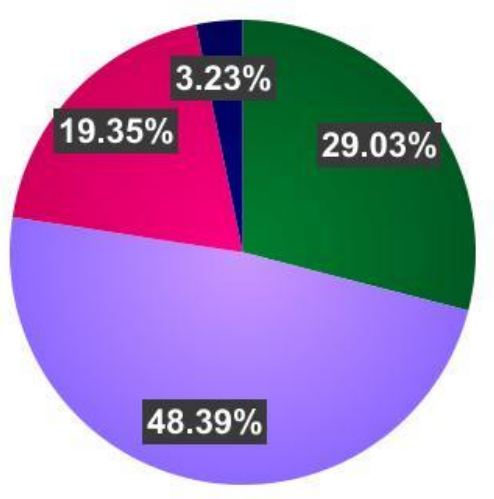

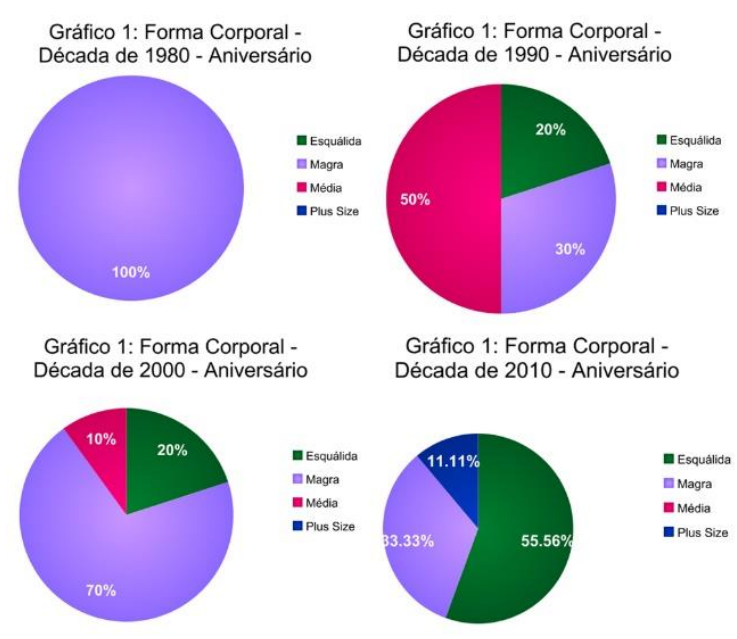

Esquálida $\square$ Magra $\square$ Média $\square$ Plus Size

Gráfico 1 - Forma Corporal

Fonte: Produzido pelas autoras

Nossa primeira observação diz respeito à forma corporal das mulheres representadas. No quadro geral, considerando todas as capas que compõem o primeiro corpus, o corpo "magro" representa esmagadora maioria, com quase 80\%, seguida de um biótipo interpretado como "médio", com quase $17 \%$ das aparições, tendo como crivo um corpo que, ainda que não seja gordo, não se enquadra no padrão de magreza comum nos espaços midiáticos. Identificamos, também, outras duas representações para essa categoria, uma marcada pela magreza exagerada, a qual denominamos "esquálida", com uma frequência de quase 3\% e outra que representa o corpo gordo, o qual classificamos "plus size", seguindo a nomenclatura designada a esse modelo corporal no universo da moda, com menos de $1 \%$ de frequência. Vemos, assim, dados que evidenciam a representação de um corpo magro, o que levanta a questão de como a mídia apresenta formas padronizadas de beleza. No mundo da moda, especificamente de revistas femininas, as definições padronizadas do corpo magro, muitas vezes esquálido, como demonstraram os últimos dados, interpelam sujeitos a adequarem-se às expectativas no que concerne à forma corporal, podendo gerar danos psicopatológicos que variam desde a baixa autoestima a doenças como anorexia nervosa.

Giordani (2006) realizou um estudo empírico visando compreender a relação entre a subjetividade e o corpo de pessoas com psicopatologias como a anorexia nervosa e bulimia. A pesquisa revelou que a imagem corporal do indivíduo não é resultado apenas de sensações táteis, mas está fortemente associada a figurações e representações sobre o corpo. É 
precisamente este o resultado que se percebe nas psicopatologias estudadas, o caso de uma imagem corporal auto-apreendida que se forma além das fronteiras físicas do corpo. $\mathrm{O}$ vínculo direto entre a representação do corpo feminino na mídia, especialmente em revistas femininas, e os distúrbios de autoimagem pode ser verificado nessa pesquisa por meio de entrevistas.

Os modelos tipificados acerca da beleza do corpo feminino que comumente têm se associado à magreza nas sociedades contemporâneas ocidentais, como agravante, resumem-se a um modelo corpóreo que desconsidera as características físicas da mulher brasileira, baseados muito mais em modelos holiudianos e europeus. Ademais, sabemos do uso de ferramentas que manipulam a imagem e a desassocia do real, já que a foto da capa é um simulacro "aperfeiçoado" do corpo real.

Samarão (2007) afirma que o corpo da mulher foi padronizado nas medidas e nos estilos, sendo este, o efeito dos discursos que dão consistência simbólica à vida social. Entendemos que a sociedade e sua cultura não são estáticos, assim como os discursos também são ressignificados ao longo do tempo. Assim, acessando os dados quantitativos, buscamos ainda analisar em que medida a padronização de modelo corporal discutida se alterou década a década. Observamos uma maior discrepância de dados comparativos ao analisar as edições de aniversário, assim, nossas atenções se voltarão, aqui, a elas. Se nos anos 80 , todas as mulheres escolhidas para estampar essas capas eram magras, na década de 90, observamos números surpreendentes, uma frequência de $50 \%$ de mulheres consideradas de biótipo "médio" figurou nesses espaços. A outra metade é formada por mulheres "magras", 30\%, e “esquálidas", 20\%. Nesta década, uma maior aproximação a modelos corporais ordinários (no sentido de comuns) ocupando essas arenas significa uma revisão dos padrões de representação e uma maior possibilidade de auto reconhecimento por parte das leitoras, ao menos no que concerne às formas corporais e nesta década específica, ainda que o corpo gordo seja completamente excluído e, assim, tido como não ideal. Nos anos 2000, notamos uma esmagadora maioria de mulheres "magras" (70\%) e "esquálidas" (20\%), restando apenas 10\% das capas para mulheres consideradas de biótipo "médio". Vemos, assim, um retrocesso no que se refere à pluralidade de formas e, novamente, a total exclusão de corpos considerados gordos. Se na década seguinte, ainda em curso, vemos as mulheres com corpos "esquálidos" ganharem os holofotes, em mais de $55 \%$ de todas as capas, seguidas pelas "magras", com mais de 33\%, observamos um fenômeno até então inédito nas edições de aniversário, a presença de modelos "plus size" figurando nesses espaços, com uma frequência de pouco 
mais de $11 \%$. Comparativamente, somos impelidos a afirmar que corpos magros e esquálidos continuam representando o modelo de beleza que a revista pretende promover, no entanto, a presença de formas corporais gordas deve ser evidenciada como modo de inclusão de uma tipologia até então completamente discriminada.
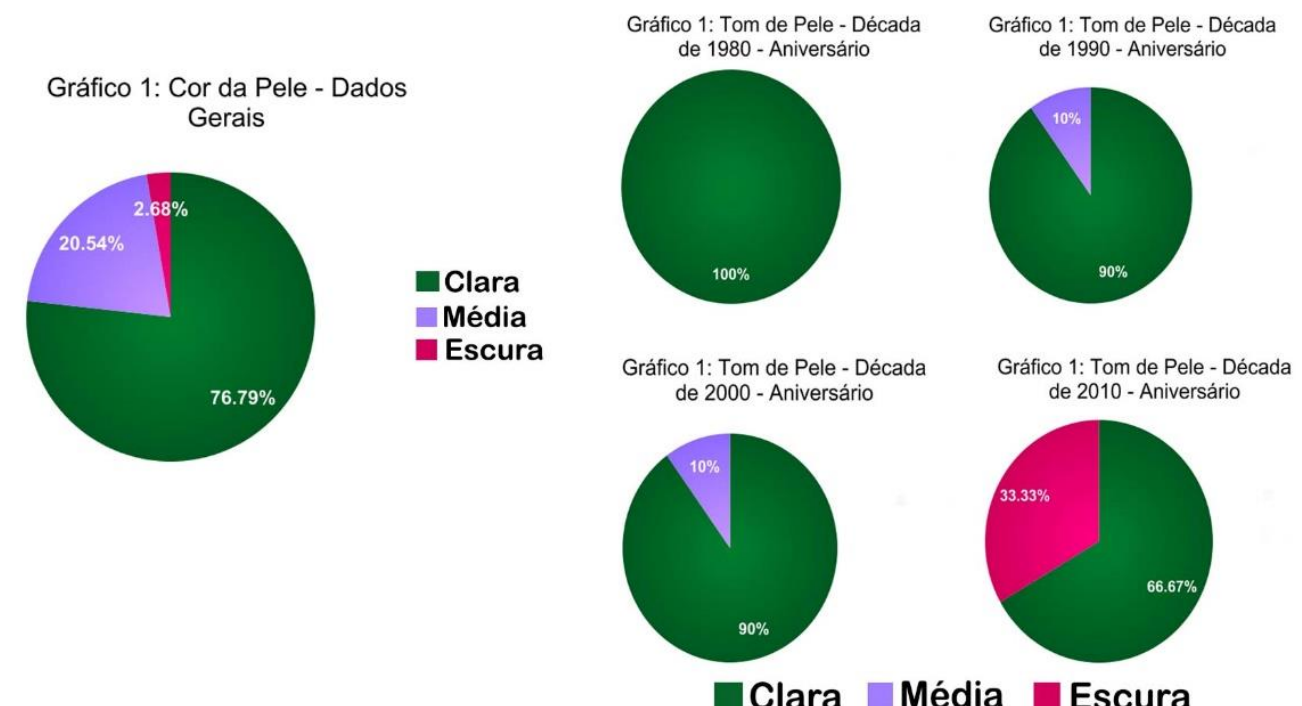
de 2010 - Aniversário

Gráfico 2 - Cor da pele Fonte: Produzido pelas autoras

Partindo para aspectos que contribuem para definir a etnia da mulher retratada no corpus, tipificamos, primeiramente, o tom de pele da mulher representada nas capas da revista. Ressaltamos, aqui, a necessidade de delimitar diferentes tons de pele e que não buscamos definir a qual raça essa mulher se encaixa. Isso porque nossa intenção não é apenas quantificar as aparições de mulheres negras e brancas nas capas, mas também compreender se existe um modelo (ou modelos) de mulher branca e negra ali presente e, mais além, se outros modelos, no que concerne aos traços étnicos-raciais, são invisibilizados. Recorrendo aos números gerais, tendo o primeiro corpus como base, deparamo-nos com dados alarmantes. Mais de $76 \%$ de mulheres brancas estamparam as capas das revistas ELLE ao longo dos anos, e, entre as negras, mais de $20 \%$ apresentavam pele negra mais clara, por vezes modificada por técnicas de iluminação, com intuito explícito de branqueá-la, por vezes pela própria maquiagem, buscando um ar de bronzeamento ao tom. Menos de 3\% das mulheres negras representadas possuem pele escura. A realidade ora exposta se agrava ainda mais ao considerarmos que a revista é publicada no Brasil, um país miscigenado em que a raça negra 
supera a branca - segundo dados do IBGE de $2010^{3}$ são 50,7\% de negros no país - e que a terceira região onde a revista possui o maior número de leitoras é a região nordeste, local de grande concentração da população negra.

Pontuamos, aqui, que o conceito de raça não é por nós compreendido sob lentes essencialistas, tratando-se de um conjunto de fenótipos e aspectos biológicos, mas sim, como defende Stuart Hall (2003), uma construção social e política, baseada em atributos fenotípicos, mas determinada pela relação de poder entre grupos raciais e pelas vivências culturais e simbólicas. É exatamente dessa relação de poder que surge o racismo, o qual se expressa de diferentes formas e sentidos, mas que, invariavelmente separa dominantes e dominados, privilegiados e não privilegiados. Os números que acabados de analisar devem ser considerados retratos do racismo no Brasil, onde o modelo de beleza ideal é baseado em fenótipos da mulher branca, com traços europeus. Mais além, a quase ausente representação de mulheres negras com pele escura traz à tona o chamado "racismo de marca", já anteriormente discutido. Partindo desse princípio, o parâmetro mais relevante é a cor da pele, independente da diversidade étnica na matriz familiar.

Já em uma fase mais descritiva das análises, observamos mulheres de diferentes tons de pele branca, ora para acentuar a pele pálida, "quase de porcelana" $(25,35 \%)$, ora para garantir um tom mais corado e rosado $(28,17 \%)$. No entanto, o tom preponderante foi o que consideramos bronzeado ou levemente bronzeado (46,48\%). Evidenciamos, aqui, uma tentativa de tornar a pele branca mais morena, com características mais vivas, praianas, típica de um país tropical como o nosso, no entanto, sem descaracterizá-la do grupo racial ao qual ela faz parte e representa.

Aqui, é importante mencionar que a discussão racial, especialmente nos sistemas simbólicos de representação, não emerge somente quando nos deparamos com representações estereotipadas e estigmatizadas do negro, mas surge, também, quando nos atentamos para o jogo de presenças e ausências. Aquelas identidades que ocupam a arena das representações são as hegemônicas, naturalizadas e definidoras da 'norma' do que é comum, belo, aceitável, desejável, enquanto aquelas que fogem à regra costumam ser percebidas como 'a outra', a que não pertence. A invisibilidade seria, assim, uma forma de aculturar esse jogo.

No que concerne à comparação de resultados, década a década, dados mais significativos foram, de fato, observados nas edições de aniversário da Revista. Se nas primeiras três décadas a pele branca ocupou essas capas, tidas como especiais, quase que

\footnotetext{
${ }^{3}$ http://pt.globalvoicesonline.org/2011/11/24/brasil-censo-populacao-negra/ 
completamente, invisibilizando mulheres negras - $100 \%$ de brancas nos anos $80,90 \%$ nos anos 90 e $90 \%$ nos anos 2000, sendo os $10 \%$ restantes de mulheres negras com pele clara -, nesta última década vimos uma mudança expressiva no que se refere à representação étnicoracial. Ainda observamos uma maioria branca (pouco mais de 66\%), porém, as mais de $33 \%$ de mulheres negras que estamparam as edições de aniversário, a partir de 2010, apresentaram pele escura, um modelo pouco visto ao longo da história da revista e, possivelmente, um sinal de mudança.

Ao colocarmos em pauta questões étnico-raciais, outros aspectos além da cor da pele merecem destaque e análise. Características como o tipo de cabelo são de extrema relevância para a identidade racial. Nesse sentido faz-se necessário analisar além do visual apresentado na imagem, e entender que tipo de cabelo é representado como construtor de uma identidade bela.

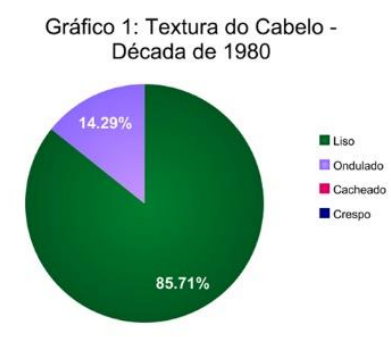

Gráfico 1: Textura do Cabelo Década de 2000

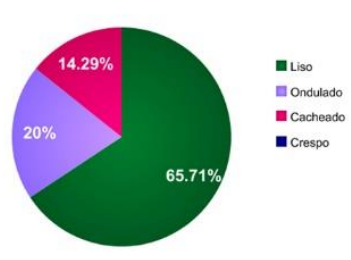

Liso Ondulado Cacheado $\square$ Crespo

Gráfico 1: Textura do Cabelo Década de 2010
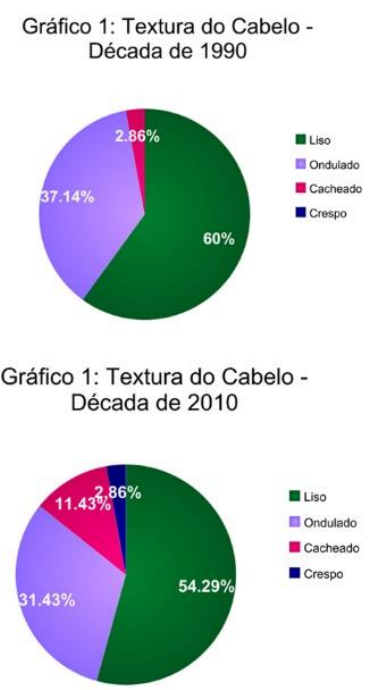

Gráfico 3 - Textura do cabelo

Fonte: Produzido pelas autoras

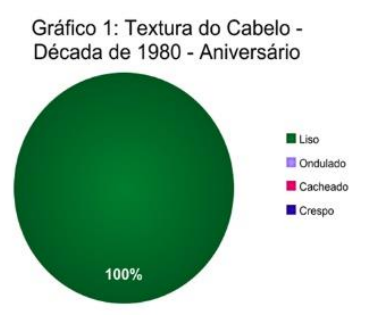
Gráfico 1: Textura do Cabelo -
Década de 1990 - Aniversário
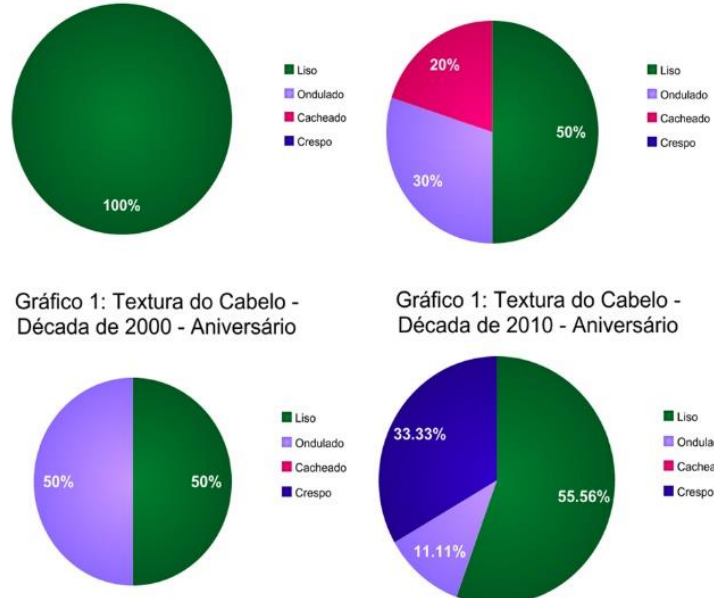

Gráfico 1: Textura do Cabelo Década de 2010 - Aniversário

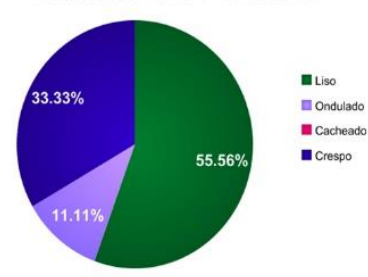

Liso Ondulado $\square$ Cacheado $\square$ Crespo

Como apresentado por meio dos gráficos, a porcentagem de aparições de cabelos lisos, em todas as décadas, é esmagadora, sempre superior a 50\%, refletindo na cultura que induz ao crédito do belo estar associado a uma textura específica de cabelo, o mais liso possível. Apesar de no Brasil a miscigenação ser fato notório (DAMATTA, 2000), evidenciando uma maioria de mulheres de cabelos naturalmente encaracolados ou crespos (FREYRE,1987), o fio liso representa o preferido, o sonhado, indicando que o branqueamento ideológico ainda persiste. Segundo pesquisa realizada em 2013 pela consultora Kantar Worldpanel e publicada 
pela revista Exame $^{4}$, estima-se que cerca de $70 \%$ dos brasileiros tenham fios de cabelo ondulados ou crespos e que 25 milhões de mulheres brasileiras alisam o cabelo.

Entendemos que a mídia é fator decisivo para a construção do imaginário coletivo que cria como ideal um modelo de beleza. Nesse cenário, quanto mais distante desse ideal um cabelo aparenta ser, mais estigmatizado e rejeitado ele é, ao ponto de ser naturalizado o termo “cabelo ruim" para cabelos crespos. Essa obsessão pelo que diríamos "padrão" de cabelo, ativa e mantém um mercado, criando um ciclo entre consumo e insatisfação.

A sociedade de consumo tem como base de suas alegações a promessa de satisfazer os desejos humanos em um grau que nenhuma sociedade do passado pôde alcançar, ou mesmo sonhar, mas a promessa de satisfação só permanece sedutora enquanto o desejo continua insatisfeito; mais importante ainda, quando o cliente não está "plenamente satisfeito" [...]. [...] A sociedade de consumo prospera enquanto consegue tornar perpétua a nãosatisfação de seus membros (e assim, em seus próprios termos, a infelicidade deles) [...]: satisfazendo cada necessidade/desejo/vontade de tal maneira que eles só podem dar origem a necessidades/desejos/vontades ainda mais novos. (BAUMAN, 2007, p. 63-64)

Ao nos atentarmos às peculiaridades dos dados quantitativos, observamos o aumento de cabelos ondulados ao longo das décadas, nos anos 80 percebemos um percentual baixo de cabelos ondulados, 14,29\%, sendo todos os demais lisos, quando, nos anos de 1990, notamos pouco mais de 37\%. De 2000 a 2010, a frequência de cabelo ondulados diminuiu para $20 \%$. Nos anos seguintes, os cabelos ondulados concorrem com as aparições de cabelos lisos, quase $32 \%$ de cabelos ondulados contra pouco mais de $54 \%$ de cabelos lisos. É essencial ressaltar alguns aspectos interpretativos. Essa textura ondulada passa evidentemente por processos de modificação, seja por meio de escovas, babyliss, ou por tratamentos químicos, o cabelo ondulado representado nas capas não é um cabelo natural, mas com ondas deliberadamente fabricadas.

Ao focarmos nos cabelos cacheados e crespos, percebemos que estes possuem pouca representatividade, nas décadas de 80 e 90, os números são inexpressivos, cacheados 2,86\% e nenhuma representação dos crespos. Um quadro semelhante é visto entre 2000 a 2010, apesar de haver um crescimento, com 2,86\% crespos e 11,43\% cacheados. Vale acrescentar que parte das aparições de cabelos cacheados é advinda de um cabelo não natural e, em sua maioria, de cabelos genuinamente lisos, representados por mulheres brancas. Ainda assim, ponderamos

\footnotetext{
${ }^{4}$ http://exame.abril.com.br/revista-exame/edicoes/1051/noticias/a-patria-de-chapinha
} 
que é a partir de 2010 que o cabelo naturalmente crespo é representado na capa de uma revista ELLE. Se até então todas as poucas mulheres negras que ocuparam esses espaços tiveram seus cabelos alisados, observamos uma mudança, ainda que modesta, de um fenômeno que possivelmente esteja em emergência e que melhor se expressa nas edições de aniversário.

Nessas edições especiais, ainda que os cabelos lisos estampem a maioria das capas, percebemos, ao observar os gráficos, que é a partir de 2010 que os cabelos crespos ganham destaque, ocupando a segunda maior porcentagem, com 33,33\% de frequência. Entendemos que esses números retratam uma nova sociedade, que passa a valorizar cabelos naturalmente crespos. Provavelmente, a atuação de movimentos feministas de mulheres negras no Brasil, especialmente em espaços virtuais - como os blogs Blogueiras Negras, Geledés, Meninas Black Power, Encrespando e Aumente o Volume, todos com números expressivos de seguidores -, atrelada à maior conscientização da importância de manter as raízes como forma de resistência e de empoderamento, sejam fatores importantes e influenciadores. Movimentos de mulheres que defendem o uso de turbantes, símbolo da cultura afro, também são recentes e ganham proporções cada vez maiores, inclusive em projetos desenvolvidos em escolas e outros espaços políticos. Certamente esse fenômeno merece discussão e reflexão, porém, não nos propomos a esse aprofundamento nesse espaço por não dizer respeito ao nosso objeto de estudo e porque o limite de páginas de um artigo científico nos cerceia.

Retomando as análises, compomos uma série de outras categorias associadas a raça e etnia, as quais revelam características da mulher representada pela Revista. Não esporemos aqui todos os resultados, por serem vastos, contudo, pontuaremos os mais relevantes. Entendemos que a cor dos olhos e o formato dos lábios estão entre os mais significativos nesse conjunto de elementos quantificados ao longo da pesquisa empírica.

Gráfico: Olhos - Dados Gerais

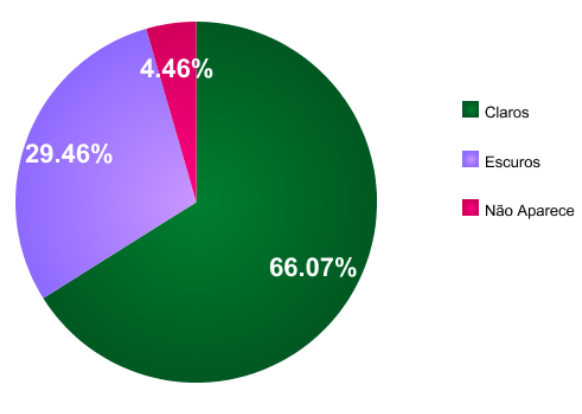

Gráfico: Boca - Dados Gerais

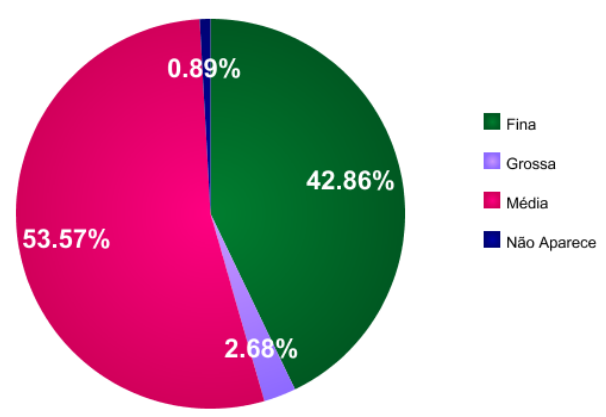

Gráfico 4 - Cor dos olhos e formato de boca Fonte: Produzido pelas autoras 
Entendemos que a espessura dos lábios possui relação direta com traços raciais e que, de modo geral, mulheres brancas possuem lábios mais finos que mulheres negras. Para a fase de codificação de categorias, definimos três modelos labiais, "finos", "médios" e “grossos". Nos dados gerais, foram quase $54 \%$ de lábios considerados médios e pouco mais de $42 \%$ de finos, sobrando menos de $3 \%$ para os lábios grossos. Observamos que o engrossar dos lábios foi frequentemente realizado por meio de batons, entre outros recursos, demonstrando assim uma intenção clara em alterar sua característica original. Lábios mais “carnudos" estão diretamente relacionados à sensualidade da mulher - imagem construída e reforçada pela mídia -, tanto é que procedimentos cirúrgicos e químicos são realizados para tal. No entanto, a distinção racial se mantém, considerando que lábios grossos, supostamente característicos de mulheres negras, foram pouco vistos no corpus.

Segundo Lipovetsky (2000), a publicidade exerceu influência sobre a definição de determinadas características femininas tidas como sensuais. No século XX, impulsionado pelo capitalismo e, especificamente pela moda, o mercado de cosméticos aparece como solução para "imperfeições", o que resultou na fomentação da cultura da aparência feminina para um número maior de mulheres (LIPOVETSKY, 2000). Neste processo, a exibição da mulher como sensual ganhou representação.

A sedução se transformou em um processo geral que tende a normatizar, dentre outros aspectos, o consumo. O corpo feminino transformou-se em 'arma' para a publicidade e é mostrado, sempre que possível, com um mínimo de roupa. Beleza, sensualidade e erotismo são armas privilegiadas para prender a atenção do público (LIPOVETSKY, 2000, p.164).

Essa sensualidade, que tem forte apelo a partir do formato dos lábios, não se expressa em um lábio negro, mas por lábios carnudos com características híbridas, de um lábio medianamente grosso, sem características tidas como negroides. " $O$ que se valoriza é uma estética híbrida, que combina traços negros e estética branca". (STROZENBERG, 2005, p. 210).

Em uma etapa de interpretação mais aprofundada das análises, observamos que, se encontramos um grande número de mulheres brancas apresentadas com lábios "engrossados" artificialmente, supostamente sensualizados, a maioria esmagadora das mulheres negras exibidas nas capas não possui determinadas características afrodescentes e, especificamente no que concerne ao lábio, não apenas lábios grossos foram excluídos dessa representação, como os finos preponderaram. Essa é, explicitamente, uma forma de branqueamento de traços negroides, assim, mesmo que mulheres negras se façam presentes, com alguma frequência, é 
o padrão do belo branco que prevalece. Uma forma de delimitar qual modelo de negritude é aceitável, aquela que, em alguma medida, mantém características da descendência Europeia.

A preferência por olhos claros - quase $67 \%$ das capas representam mulheres de olhos verdes ou azuis -, descortina, de acordo com Hema Sundaram (2003), o eurocentrismo hegemônico. A autora, que estuda a história da beleza no mundo, aponta que, para as mulheres, em particular, pele clara e olhos claros se mantêm como indicadores de fertilidade e beleza. Dados estatísticos são reveladores, a Estônia é o país com o maior percentual de pessoas com olhos claros, com quase $98 \%$ de casos. Nações do norte europeu, como Noruega, Suécia, Finlândia, Dinamarca, Islândia, também possuem a grande maioria da população com olhos claros, com quase 90\%. Outros países europeus, como Holanda, Escócia e Alemanha, também apresentam uma grande proporção, nos Países Baixos, cerca de $80 \%$ e na Alemanha quase $70 \%$. Em contrapartida, as populações dos continentes Africanos e Asiáticos raramente possuem olhos naturalmente claros, sendo esta característica da miscigenação. Mesmo considerando ser o Brasil um país miscigenado, o gene dominante é o castanho, assim, olhos claros estão diretamente relacionados à ancestralidade europeia.

Apesar de não apresentarmos aqui o detalhamento de todos os resultados obtidos a partir desta pesquisa, já que outras categorias foram analisadas referentes às formas de representação da mulher no corpus, a partir do que pudemos expor, é possível afirmar que as capas da ELLE Brasil reforçam um perfil estético de mulher, pautado no eurocentrismo, com pele branca, nariz fino, boca média ou fina, olhos claros e, como complemento, rostos finos e alongados. Essa padronização, como ressalta BOHM (2004), é ao mesmo tempo reflexo do racismo velado em voga no Brasil, assim como forma de reforçá-lo e alimentá-lo.

(...) apesar de o racismo não ser declarado, posto que proibido, nas revistas femininas, a realidade é maquiada e o negro raramente aparece. A hegemonia branca, então, acaba sendo um fator de forte identificação: aprendemos a gostar de pessoas claras, de cabelos lisos, de preferência loiros, de olhos igualmente claros, nariz fino e boca delineada.

Entendemos, assim, que o belo é social e culturalmente construído a partir de uma combinação de elementos simbólicos e não simbólicos os quais contribuem para a exclusão e manutenção do modelo hegemônico que, muito além de se apresentar como "gosto", se mostra alicerce de relações de poder com fortes consequências sociais. 


\section{CONSIDERAÇÕES}

Seguindo a trajetória do teórico e do empírico, primeiramente realizamos uma revisão bibliográfica alicerçada nos Estudos Culturais com o intuito de compreender como a identidade se constrói culturalmente. Entendemos que no jogo das diferenças, identidades são elencadas como hegemônicas e se mantêm horizontalmente, aculturadas como ideal - de beleza, de comportamento. Nesse processo, as representações se mostram relevantes. Os sistemas simbólicos, como os midiáticos, são palco destas representações e impactam a sociedade, já que corroboram para a naturalização de identidades dominantes, podendo, também, servir à contra hegemonia, ao trazer para o palco as menos privilegiadas, consideradas minorias.

No campo do empírico, após a análise do corpus, chegamos a algumas conclusões. No que concerne aos dados gerais que, de forma representativa, são generalizáveis às representações das capas da ELLE ao longo de sua história no Brasil, o corpo "magro" é maioria absoluta nas imagens apresentadas pela revista ao longo dos anos. No universo da moda, especificamente de revistas femininas, as definições padronizadas do corpo magro, por vezes esquálido, interpelam sujeitos à adequação às expectativas em torno do "corpo ideal". No que se refere a características étnico-raciais, deparamo-nos com dados alarmantes. Uma maioria esmagadora de mulheres brancas ocuparam as capas das revistas ELLE ao longo dos anos, e, entre as negras, quase todas apresentavam pele negra mais clara, por vezes notoriamente clareada por técnica de iluminação, por vezes pela própria maquiagem. Menos de $3 \%$ das mulheres negras representadas possuem pele escura. Pontuamos que estes dados são o retrato do racismo no Brasil, considerando que o modelo de beleza ideal é determinado por fenótipos da mulher branca, com traços europeus. Outros dados corroboram essa afirmação, a presença muito maior de cabelos lisos em detrimento dos demais e ausência quase que absoluta de cabelos crespos; uma maioria de mulheres louras ocupando as capas dados não apresentados neste artigo, mas mensurados ao longo da pesquisa -, olhos claros encontrados com muito mais frequência do que os escuros; quase que total ausência de lábios considerados grossos e formatos redondos de nariz, traços característicos da raça negra. Ademais, a quase ausência de mulheres negras com pele escura nas capas da revista descortina o denominado "racismo de marca", quanto mais traços negroides, mais discriminação racial. Invariavelmente a Revista tenta clarear, afinar e alongar as mulheres da sua capa, quando não escolhem um "modelo pronto" de mulher europeia. Reforçamos que o 
racismo nos sistemas simbólicos não se configura apenas quando representações estereotipadas e estigmatizadas do negro se fazem presentes, mas também por meio do silenciamento de da invisibilidade. Assim, não representar é uma das facetas do racismo.

Ao focarmos nossas atenções às edições de aniversário, consideradas espaços significativos de representação, encontramos resultados que nos direcionam a ponderar uma possível mudança em emergência. Especialmente na última década, ainda em curso, deparamo-nos com números que apontam para uma maior diversidade de representações. A magreza continua em voga e, até, de forma extrema, com uma maioria de mulheres esquálidas. Porém, observamos um fenômeno inédito nas edições de aniversário, a presença de modelos "plus size" figurando nesses espaços, e o consideramos uma forma de inclusão de uma tipologia até então completamente discriminada. Nesta última década identificamos, também, uma mudança expressiva no que concerne à representação étnico-racial. Ainda vimos uma maioria branca, porém, um terço das capas apresenta mulheres negras de pele escura, um modelo não representado ao longo da história da revista. Os cabelos crespos também ganharam destaque a partir de 2010, ocupando a segunda maior porcentagem.

Representar a mulher brasileira demanda diversidade, considerando a miscigenação característica de um país originalmente indígena, que recebeu muitos imigrantes europeus e escravizou negros africanos. Nas edições de aniversário é possível ver uma mudança, ainda em processo, onde corpos gordos, mulheres negras de pele escura e com traços marcantes da sua raça são respeitadas, o que pode ser reflexo de uma sociedade mais crítica, que sofre influência não apenas de meios de comunicação tradicionais e massivos, mas também de espaços mais democráticos de compartilhamento, nos quais outras vozes ecoam, de militância e resistência, que lutam por representação e reconhecimento. Possivelmente a Revista ELLE tenha começado a escutar essas vozes e a construir uma nova história de representação e inclusão.

\section{REFERÊNCIAS}

AAKER, D. A Pesquisa de Marketing. São Paulo: Atlas, 2004.

ALAKIJA, A. Mídia e identidade negra. In: BORGES, R. C. S (Org.). Mídia e

Racismo. Brasília, DF: ABPN, 2012.

BARDIN, L. Análise de conteúdo. Lisboa, Edições 70, 1997.

BAUMAN, Z. Vida para consumo: a transformação das pessoas em mercadoria. Rio de Janeiro: Jorge Zahar, 2007. 
BOHM, C. C. Um peso, uma medida. O padrão de beleza feminina apresentado por três revistas brasileiras. São Paulo: Uniban, 2004.

BUTLER, J. Problemas de gênero: feminismo e subversão da identidade. Tradução de Renato Aguiar. 8a . ed. Rio de Janeiro: Civilização Brasileira, 2015.

CARNEIRO, S. Mulheres em Movimento. Estudos Avançados. v. 17, n. 49, p.117-132. 2003.

DAMATTA, R. O que faz o brasil, Brasil? 11. ed. Rio de Janeiro: Rocco, 2000.

FELERICO, S. P.G. Do Corpo Desmedido ao Corpo Ultramedido. A revisão do corpo na Revista Veja de 1968 a 2010. Tese (Doutorado em Comunicação e Semiótica) Pontifícia Universidade Católica de São Paulo. São Paulo, 2010.

FREYRE, G. Modos de homem e modas de mulher. Rio de Janeiro: Record, 1987.

GIORDANI, R. C. F. A auto-imagem corporal na anorexia nervosa: uma abordagem sociológica. Psicologia \& Sociedade; v.18, n.2, p. 81-88. 2006.

HALL, S. Da Diáspora: Identidades e mediações culturais. Belo Horizonte: Editora UFMG, 2003.

HALL, S. A identidade cultural na pós-modernidade. 11. ed. Rio de Janeiro: DP\&A, 2006.

LIPOVETSKY, Gilles. A terceira mulher. São Paulo: Companhia das Letras, 2000.

LOURO, G. L. O corpo educado: pedagogias da sexualidade. Belo Horizonte: Autêntica, 1999.

NASCIMENTO, A. O genocídio do negro brasileiro: processo de um racismo mascarado. Paz e Terra, 1978.

NOGUEIRA, O. Preconceito racial de marca e preconceito racial de origem: Sugestão de um quadro de referência para a interpretação do material sobre relações raciais no Brasil. Tempo social, Revista de sociologia da USP, v.19, n 1, p.287-308, 2006.

SAMARÃO, L. O espetáculo da publicidade: a representação do corpo feminino na mídia. Comunicação, mídia e consumo. São Paulo: ESPM, vol.3, n.8, p. 46-57, 2007.

SILVA T. T. A Produção Social da Identidade e da Diferença. In: SILVA, T. T. (org.). Identidade e Diferença: A perspectiva dos Estudos Culturais. Petrópolis: Editora Vozes, 2007.

STROZENBERG, I. O apelo da cor: percepções dos consumidores sobre as imagens da diferença racial na propaganda brasileira. Comunicação Mídia e Consumo, v. 2, n. 4, p. 199$220,2005$. 
SUNDARAM, H. Face Value: The Truth about Beauty. New York: Rodale Books, 2003.

WOODWARD, K. Identidade e Diferença: uma introdução teórica e conceitual. In: SILVA, T. T. Identidade e diferença: a perspectiva dos estudos culturais. Petrópolis: Vozes, 2007.

Professora efetiva do Departamento de Comunicação Social da UFS (Universidade Federal do Sergipe). Professora Permanente do Programa de Pós Graduação Stricto Sensu em Comunicação Social (PPGCOM) da Universidade Federal de Sergipe. Coordenadora no Brasil do grupo de pesquisa CHISGAP (Critical, Historical and international Studies on Gender and Press) - grupo de pesquisa que tem como foco o estudo de gênero na mídia impressa sob uma perspectiva crítica. Doutora em COMUNICAÇÃO SOCIAL pela Universidade Metodista de São Paulo - UMESP (2013); DoutoradoSanduíche (PDSE) concluído e realizado em Carleton University, Ottawa, Canadá (2012); Mestre em COMUNICAÇÃO MIDIÁTICA pela Universidade Estadual Paulista - UNESP (2009); Possui graduação em COMUNICAÇÃO SOCIALcom habilitação em jornalismo pela Universidade Metodista de São Paulo (2000). Tem experiência na área de Comunicação, atuando principalmente nos seguintes temas: Estudos de Gênero e mídia, cultura, publicidade, consumo e pós-modernidade, representação social.

Carla Jullyene Lima Santos Graduada em Publicidade e Propaganda pela Universidade Federal de Sergipe

Maria Nayane de Sousa Pinto Graduada em Publicidade e Propaganda pela Universidade Federal de Sergipe Esta obra está licenciada sob uma Licença Creative Commons. 